\title{
O REPÓRTER-AMADOR: as disposições sociais de Lucas do Face
}

THE AMATEUR REPORTER: the social dispositions of Lucas do Face

\author{
Letícia Maria de Souza Silva* \\ Sheila Borges de Oliveira** \\ Rayanne Elisã da Silva Santos***
}

\section{Resumo}

Neste artigo, analisamos quais são as motivações sociais que levam um cidadão, sem formação na área de comunicação, a produzir notícia à revelia dos veículos da grande imprensa. A pesquisa foi realizada com o apoio do Programa Institucional de Bolsas de Iniciação Científica (Pibic/CNPq). Neste trabalho, apresentamos os primeiros resultados gerais dos perfis sociológicos, elaborados com os indivíduos pesquisados, e mostramos de forma mais detalhada um deles, o de Lucas do Face ${ }^{1}$, que deixou de ser audiência passiva para se transformar em repórter-amador e empreendedor na Região Agreste de Pernambuco. Essa investigação acadêmica analisa o fenômeno social do repórter-amador (BORGES, 2015) com base nos aportes teórico e metodológico de Lahire (2002; 2004; 2006; 2010).

Palavras-chave: $\quad$ Disposição $\quad$ Social; $\quad$ Repórter-amador; Comunicação; Empreendedorismo.

\begin{abstract}
In this article, we analyze what are the social motivations that lead a citizen, without training in the area of communication, to produce news without the traditional media. The research was conducted with the support of the Institutional Program for Scientific Initiation Scholarships (Pibic / CNPq). In this paper, we present the first general results of the sociological profiles, elaborated with the researched individuals, and show in more detail one of them, Lucas do Face, who has gone from being a passive audience to becoming an amateur reporter and entrepreneur in the Rough region of Pernambuco State (Brazil). This academic investigation analyzes the social phenomenon of the amateur reporter (BORGES, 2015) based on Lahire's theoretical and methodological contributions (2002; 2004; 2006; 2010).
\end{abstract}

Keywords: Social Disposition; Amateur Reporter; Communication; Entrepreneurship.

\footnotetext{
* Graduanda do Curso de Comunicação Social/CAA-UFPE/Brasil. E-mail: leticiamaria_s_s@hotmail.com.

** Professora Adjunta do Curso de Comunicação Social do CAA-UFPE/Brasil. Doutorado em Sociologia pela UFPE/Brasil. E-mail: sheilaborges12@gmail.com.

*** Graduanda do Curso de Comunicação Social/CAA-UFPE/Brasil. E-mail: elisayanne@gmail.com.

${ }^{1}$ Nome fictício, objetivando preservar a identidade do participante.
} 
SILVA, Letícia M. de S.; OLIVERIA, Sheila B. de; SANTOS, Rayanne E. da S. O repórter-amador: as disposições sociais de Lucas do Face. Caos - Revista Eletrônica de Ciências Sociais. João Pessoa, n. 23, p. 233 - 250, jul./dez. 2019. Disponível em: https://periodicos.ufpb.br/ojs2/index.php/caos/index

\section{Introdução}

A proposta da pesquisa que subsidia o presente trabalho, apresentada parcialmente neste artigo, é a de estudar o cidadão, morador do Agreste de Pernambuco, iniciando por Caruaru, cidade polo daquela região, que cria um espaço próprio, principalmente nas redes sociais on-line, para fazer notícia se contrapondo às mídias tradicionais. Os critérios de noticiabilidade, para Wolf (1987), formam um conjunto de elementos que dá amparo à informação selecionada para virar notícia. É esse conjunto de regras, chamado de valores-notícia, que estabelece os critérios que controlam e administram a quantidade e o tipo de acontecimento que vai servir de base para a notícia. Esse cidadão comum, que produz notícia e é analisado na pesquisa, estabelece os seus próprios valores-notícia à revelia da chamada grande imprensa.

Esta pesquisa faz parte de um projeto maior que avalia os cidadãos do Agreste, sob os mais diversos aspectos sociais e comunicativos, por meio do Observatório de VidaAgreste, um grupo de pesquisa que agrupa professores e alunos do Centro Acadêmico do Agreste (CAA), unidade da Universidade Federal de Pernambuco (UFPE), no município de Caruaru. O grupo estuda o ator, produtor de conteúdo, elaborando perfis sociológicos de cidadãos comuns que não possuem formação especializada em alguma área da comunicação. Essa análise se iniciou por um indivíduo de Caruaru, que se contrapõe ao bloqueio imposto pela grande mídia e aos seus filtros econômicos, políticos e culturais, quando cria notícia a partir de critérios pessoais em uma página no Facebook.

Antes de apresentar o perfil em si, o trabalho de análise, na primeira fase, identifica as características gerais do grupo pesquisado, formado por esse cidadão de Caruaru e outros da região, a partir de um quadro socioeconômico e cultural. O objetivo é investigar as tendências que mais frequentemente motivam esses atores a querer: 1) consumir informação, com o intuito de se manter atualizados; 2) interagir com os veículos de comunicação, para dialogar com os jornalistas e inserir na pauta destas empresas temas que interessam ao grupo formado por esses cidadãos; e 3) produzir notícias em espaços virtuais que foram criados por esses cidadãos, geralmente em alguma rede social, para dar notoriedade aos assuntos que ficam de fora da pauta da grande imprensa. São essas três ações: consumir, interagir e produzir notícias, realizadas por esse indivíduo comum, 
SILVA, Letícia M. de S.; OLIVERIA, Sheila B. de; SANTOS, Rayanne E. da S. O repórter-amador: as disposições sociais de Lucas do Face. Caos - Revista Eletrônica de Ciências Sociais. João Pessoa, n. 23, p. 233 - 250, jul./dez. 2019. Disponível em: https://periodicos.ufpb.br/ojs2/index.php/caos/index

não necessariamente ao mesmo tempo e nessa ordem, que fundamentam o conceito de repórter-amador de Borges (2015).

$\mathrm{Na}$ segunda fase, a investigação analisa as disposições sociais desse repórteramador do Agreste, para buscar entender o que leva uma pessoa, que não é jornalista, radialista ou comunicador, a criar espaços autorais para produzir notícias, identificando os fatores sociais que o levam a se sentir motivado para exercer esse trabalho, que, inicialmente, não era remunerado. Atualmente, no entanto, parte desses repórteresamadores tem ganhado dinheiro com essa atividade, como aponta a análise feita em Caruaru.

O repórter-amador faz parte de uma sociedade que está, cada vez mais, interligada em rede. Afinal, basta o cidadão ter um computador ou qualquer outra plataforma móvel com acesso à internet, para navegar livremente e interagir com os veículos de comunicação, mandando mensagens, comentários e imagens, o que Sbarai (2011) e Moretszohn (2007) chamam de cidadão-repórter. Além de colaborar com os jornalistas, passando denúncias ou ajudando com dicas de pautas, parte desses indivíduos cria espaços virtuais nos quais ela mesma escreve notícia, sem se submeter aos filtros de edição das empresas de comunicação.

O cidadão-repórter é o ator social que interage com a grande imprensa, opinando ou sugerindo assuntos que deseja ver no telejornal ou no programa de rádio. Neste caso, são coprodutores da notícia. O repórter-amador, por sua vez, não se contenta em ser apenas colaborador. Ele possui o desejo de produzir a notícia, de apurar da sua maneira, sem precisar estar ligado a jornalistas ou veículos de comunicação. A maioria deles passou a escrever e dar publicidade à própria notícia a partir das ferramentas disponibilizadas pela rede social que mais utiliza, como, por exemplo, em lives no Facebook. Ou seja, transmissão de um fato ao vivo por aquela rede social.

Nesse contexto, o exercício do cidadão comum, que quer produzir a própria notícia, tem sido importante para as mudanças nas configurações e relações sociais que são estabelecidas pelos atores que estão dentro e fora da grande imprensa. Esse campo social do jornalismo é fechado, quase inacessível para outras pessoas que não possuem um diploma na área. Esses indivíduos têm um papel mais participativo e provocador, 
SILVA, Letícia M. de S.; OLIVERIA, Sheila B. de; SANTOS, Rayanne E. da S. O repórter-amador: as disposições sociais de Lucas do Face. Caos - Revista Eletrônica de Ciências Sociais. João Pessoa, n. 23, p. 233 - 250, jul./dez. 2019. Disponível em: https://periodicos.ufpb.br/ojs2/index.php/caos/index

contribuindo para quebrar regras, como as da concepção das notícias, e trazer mudanças estruturais ao jornalismo.

Os pesquisadores da comunicação são desafiados a aprofundar os seus estudos no sentido de identificar as disposições que o cidadão deflagra com mais força quando é impulsionado a pensar, sentir e agir para realizar determinadas ações sociais, como a que estamos focando: a de produzir notícia. É preciso entender como o ator, em meio ao emaranhado das variações inter e intraindividuais, que surgem nas fases de socialização (nos mundos sociais da familia, da escola e do trabalho), sente-se estimulado a desempenhar os papéis de produtor da informação. A pesquisa do Observatorio da VidaAgreste parte desse ponto, ampliando a investigação feita por Borges (2015) entre indivíduos que produzem notícia no Recife, focando o estudo em Caruaru.

\section{Repórter-amador: fundamentação teórica e procedimentos metodológicos}

É a tradição da sociologia disposicionalista que vai dar conta do objeto desta pesquisa, mostrando um caminho no qual se pode perceber as variações inter e intraindividuais, e como elas se manifestam em cada ator selecionado, quando analisarmos o cidadão nos mundos sociais que ele passa ao longo da sua trajetória de vida. Assim, utiliza-se como aporte teórico o programa para uma sociologia à escala do indivíduo de Lahire $(2002 ; 2004 ; 2006$; 2010). Ele apresentará as condições para analisar como o ator é resultado de uma mistura social de tendências variadas, incorporadas e externalizadas de forma singular. Além disso, ajudará a entender como a diversidade dessas experiências socializadoras pode ser absorvida de maneira distinta por cada cidadão.

A disposição é uma força interna, introjetada no indivíduo por meio dos processos de socialização e das influências das estruturas e das relações que são construídas nos mundos sociais. É a representação social de uma tendência, que é, ao mesmo tempo, 1) recebida pelo cidadão de forma plural (socializações), 2) retida de maneira singular e 3) externalizada em escala individual, mas que provoca mudanças em escala social. Para Lahire, a disposição se revela pelas ações. 
SILVA, Letícia M. de S.; OLIVERIA, Sheila B. de; SANTOS, Rayanne E. da S. O repórter-amador: as disposições sociais de Lucas do Face. Caos - Revista Eletrônica de Ciências Sociais. João Pessoa, n. 23, p. 233 - 250, jul./dez. 2019. Disponível em: https://periodicos.ufpb.br/ojs2/index.php/caos/index

Segundo Lahire (2004, p. 331), as disposições podem assumir a forma de uma paixão (disposição + forte apetência), de uma rotina (disposição + ausência de apetência) ou de um mau hábito (disposição + desgosto). Podemos encontrar dois tipos de disposição: a de crer (mental) e a de agir (comportamental). A primeira se caracteriza pelo que julgamos ser importante. A segunda pelo que estamos dispostos a fazer. É difícil separar essas duas disposições (LAHIRE, 2006).

Para ter acesso à disposição, a teoria disposicionalista vai buscar reconstruir uma realidade como ela é observada indiretamente. É um trabalho de interpretação de comportamentos e opiniões, que desvenda em que momento fatores ocorridos no passado da vida do indivíduo, acabam interferindo na ação dele. As variações individuais podem ser um objeto específico da sociologia, porque as realidades individuais estudadas são sociais, uma vez que são socialmente produzidas. Elas têm origens e lógicas sociais.

$\mathrm{O}$ ator pode ter motivações individuais para agir. As práticas jornalisticas, por ele ativadas para querer resolver um problema, entretanto, resultam em ações que vão interferir na comunidade e no próprio campo do jornalismo, a partir do momento em que passa a ter a responsabilidade de noticiar um fato, sem ter os filtros que são necessários para as empresas de comunicação. Em função da complexidade do estoque de disposições do ator, o pesquisador procura compreender as origens das variações inter e intraindividuais envolvidas no jogo do agir ativamente no jornalismo.

O conceito do agir ativamente, formulado por Borges (2015), é aplicado na pesquisa para explicar o movimento de saída desse cidadão de uma posição meramente passiva de espectador, ou de personagem secundário da narrativa jornalística, para uma posição ativa. Ele quer ir além do papel de receptor. Nesse movimento, o primeiro passo dado pelo ator é o de tomar a iniciativa de interagir com os conglomerados de comunicação, enviando comentários e sugestões de pautas.

Ao acionar essa função participativa, o cidadão pode desempenhar o papel de coprodutor do processo de produção da notícia, quando os veículos passam a considerar as opiniões enviadas pela audiência, o que acontece na maioria das vezes pela internet. Parte dos veículos que abre este espaço legitima a coprodução quando identifica, no 
SILVA, Letícia M. de S.; OLIVERIA, Sheila B. de; SANTOS, Rayanne E. da S. O repórter-amador: as disposições sociais de Lucas do Face. Caos - Revista Eletrônica de Ciências Sociais. João Pessoa, n. 23, p. 233 - 250, jul./dez. 2019. Disponível em: https://periodicos.ufpb.br/ojs2/index.php/caos/index

próprio texto da matéria, o nome do ator que colaborou. É este indivíduo que é considerado cidadão-repórter (SBARAI, 2011; MORETSZOHN, 2007).

O repórter-amador, entretanto, vai dar um segundo passo e irá mais adiante, não se contentará em atuar apenas como coprodutor. Quer produzir informação a partir de um espaço próprio para não ficar refém dos filtros que são determinados pelas empresas de comunicação, e deseja que a sociedade também possa ver um fato noticiado de outra forma. Por isso, seleciona as informações, segundo as suas perspectivas econômica, política e social. Diferentemente do cidadão-repórter, o repórter-amador não figura no texto jornalístico como colaborador, ele é o autor da notícia no espaço que ele mesmo cria, e é sobre os esquemas disposicionais deste indivíduo que a pesquisa, aqui descrita, está focada.

Para agir ativamente no mundo do jornalismo, o cidadão comum tem que acionar disposições específicas do seu esquema disposicional com o objetivo de colaborar e produzir notícia. Assim, o movimento de ação fica completo. O repórter- amador, quando age ativamente no jornalismo, conforme Borges (2015), não é remunerado. Na investigação em Caruaru, contudo, há uma mudança no conceito original, pois, no Agreste, o repórter-amador começa a ser remunerado para produzir notícia, chegando muitas vezes a se manter ou ter uma contribuição da renda por meio de um espaço próprio, criado no Facebook. Na pesquisa de Borges (2015), na Região Metropolitana do Recife, as ações do repórter-amador são atividades de forma voluntária, ligadas ao tempo livre, dedicado ao prazer de ler, de se informar, de escrever ou de reivindicar melhores condições de vida para as comunidades.

Nesse sentido, para Borges, não havia uma rotina diária fixa e tempo prédeterminado para executar esses dois movimentos - o de colaborar com os conglomerados de comunicação e o de escrever a própria notícia em seu espaço autoral -, impulsionados por uma força interna que movia inconscientemente o pensar e o agir do repórter-amador. O tempo dedicado a eles era o do descanso. Isso porque essas práticas, observadas pela autora, não faziam parte das atividades do trabalho remunerado, que é priorizado e para o qual o indivíduo dedica a maior parte do tempo. Daí, a designação de amador. 
SILVA, Letícia M. de S.; OLIVERIA, Sheila B. de; SANTOS, Rayanne E. da S. O repórter-amador: as disposições sociais de Lucas do Face. Caos - Revista Eletrônica de Ciências Sociais. João Pessoa, n. 23, p. 233 - 250, jul./dez. 2019. Disponível em: https://periodicos.ufpb.br/ojs2/index.php/caos/index

Mas na pesquisa no Agreste, feita como um prolongamento da investigação do doutorado de Borges, percebemos que, nessa região, o repórter-amador, começa a se profissionalizar a partir do momento que dedica mais do que o horário livre para realização da atividade. Por isso mesmo, estabelece rotinas, mesmo que não seja as de um jornalista, para dar conta das demandas diárias que passa a ter. Tanto que, além de realizar esse fluxo, ele também começa a contratar outras pessoas para ajudar na produção do conteúdo e conseguir manter as demandas. Ou seja, exerce a capacidade de empreender um negócio no Agreste a partir da motivação para escrever notícia, mesmo sem nenhum preparo mais especializado.

O repórter-amador, cujo perfil sociológico será apresentado aqui, segue, mesmo que intuitivamente, um processo de apuração, redação e edição das notícias. Esse processo, contudo, não faz parte do foco deste artigo. Mas, apesar dessa mudança, ele ainda pode ser chamado de amador, pois ama a atividade que abraça, agora, de forma mais profissional por ganhar dinheiro com ela. Não é um jornalista com formação acadêmica. Mas é um produtor de conteúdo dentro do conceito do repórter-amador.

A teoria disposicionalista envolve as noções de disposição, inclinação, propensão, hábito, tendência e pluralidade das disposições incorporadas. Está dentro de uma grande tradição teórica que é a das teorias da ação. Segundo Lahire (2002), nas teorias da ação, existem dois grupos: um que enfatiza os princípios unificadores e homogêneos, colocando um peso grande no passado e não valorizando características singulares do indivíduo e o contexto imediato da ação; no segundo grupo, estão os estudos que buscam a fragmentação interna das experiências. Ele não delega tanta importância ao passado, antes preocupa-se em ressaltar a multiplicidade das experiências vividas e o estudo das ações inconscientes, do senso de improvisação, mas não prioriza o que na ação presente depende do passado incorporado dos atores.

Entendemos que nem o primeiro nem o segundo grupo das teorias da ação e do ator, poderiam dar conta do fenômeno que buscamos compreender. Lahire é o autor que trouxe maior contribuição à pesquisa sobre o repórter-amador, porque defende o estudo sobre as diversas formas de reflexão que agem nos diferentes tipos de ação. Ou seja, defende uma sociologia da pluralidade, por meio da qual o pesquisador pode reconstruir 
SILVA, Letícia M. de S.; OLIVERIA, Sheila B. de; SANTOS, Rayanne E. da S. O repórter-amador: as disposições sociais de Lucas do Face. Caos - Revista Eletrônica de Ciências Sociais. João Pessoa, n. 23, p. 233 - 250, jul./dez. 2019. Disponível em: https://periodicos.ufpb.br/ojs2/index.php/caos/index

o universo social do indivíduo que analisa, dentro dos mundos da família, da escola, do trabalho, da comunidade, entre outros.

Os esquemas disposicionais são compostos por um conjunto de disposições ou tendências, acionados quando o indivíduo pensa, sente e age. São individuais e intransferíveis, construídos a partir das experiências vivenciadas por cada ator nos mundos sociais. Os esquemas não são fechados e estanques, são flexíveis, o que faz com que o indivíduo se adapte aos contextos vividos.

À medida que o indivíduo vive cada experiência, ele vai ativando e inibindo várias disposições, acionando inconscientemente as mais adequadas ao que necessitar para agir ativamente no jornalismo e desempenhar o papel de repórter-amador. Existem motivações que fazem o ator acionar esses esquemas. Borges (2015) identificou como eles são construídos e ativados pelo repórter-amador no Recife. Partiu do pressuposto de que a disposição para agir ativamente no jornalismo está vinculada à capacidade de mobilizar determinadas competências para querer: 1) se expressar, 2) buscar informação mesmo que isso envolva algum grau de dificuldade, 3) resolver problemas coletivos, 4) mobilizar o outro, 5) dialogar com jornalistas e veículos de comunicação, 6) acompanhar as notícias que são divulgadas pela grande imprensa e 7) encontrar alternativas próprias de comunicação. Essas motivações também foram identificadas como as principais molas propulsoras do repórter-amador no Agreste. Tanto que lá ele, diferentemente do que ocorreu no Recife, segundo Borges (2015), passou a ganhar a vida com essa atividade.

Para compreender como o cidadão comum constrói o esquema disposicional que o leva a querer ser repórter-amador, explica-se agora a metodologia que será aplicada na pesquisa. Ela parte do pressuposto de que são determinadas disposições sociais que levam o cidadão a desempenhar o papel de repórter-amador, como Borges (2015) verificou em seu trabalho, tendo como referência a metodologia de Lahire para analisar, de um ângulo diferente, o universo do indivíduo que se sente motivado a realizar práticas jornalísticas de forma voluntária.

Os esquemas disposicionais nunca são mostrados de forma direta, só são revelados a partir da interpretação de múltiplos traços de uma realidade reconstruída por meio da qual se encontram as origens das variações disposicionais, que contribuem para o 
SILVA, Letícia M. de S.; OLIVERIA, Sheila B. de; SANTOS, Rayanne E. da S. O repórter-amador: as disposições sociais de Lucas do Face. Caos - Revista Eletrônica de Ciências Sociais. João Pessoa, n. 23, p. 233 - 250, jul./dez. 2019. Disponível em: https://periodicos.ufpb.br/ojs2/index.php/caos/index

surgimento de novas ações. Tem-se acesso aos esquemas disposicionais processados inconscientemente pelo ator, por meio de observação direta, consulta a documentos, entrevistas ou questionários. Primeiramente, aplicamos questionários e realizamos entrevistas simples com um grupo de nove participantes identificados como repórteresamadores, os resultados levaram-nos a montar um quadro socioeconômico dos atores. $\mathrm{Na}$ segunda fase, realizaram-se as entrevistas em profundidade e de forma sucessiva com cada um deles. As entrevistas foram gravadas e decupadas com a autorização do entrevistado, para que sejam utilizadas na análise.

\section{Repórter-amador: os resultados das duas fases da pesquisa}

O questionário da primeira fase foi extenso, apresentou 123 perguntas para que se pudesse fazer uma incursão exploratória. Essa radiografia contextual mostra como algumas disposições se transformam em ações sob determinadas circunstâncias. Muitas das perguntas foram diretas para descobrir as características gerais dos nove atores analisados na primeira fase, para, em seguida, selecionarmos os três que participaram da segunda fase, na qual foi trabalhado o perfil sociológico dos selecionados.

O grupo inicial era formado majoritariamente por indivíduos do sexo masculino (66,7\%), contra 33,3\% de mulheres. Os participantes tinham idades entre 19 e 43 anos. Três deles nasceram em Caruaru, os demais são de Bezerros, Belo Jardim, São Joaquim do Monte, Toritama, Limoeiro e Recife. Em relação ao mundo da família, a maioria do grupo era solteira $(55,6 \%), 33,3 \%$ eram casados e $11,1 \%$ declararam que vivem em união estável. No mundo da comunidade, por um lado, apenas 33,3\% participaram de alguma associação ou outro tipo de entidade ligada ao bairro onde moram ou ao campo no qual atuam, já, por outro lado, 55,6\% realizaram trabalho voluntário em áreas sociais. O que nos sinaliza uma disposição para ajudar o próximo.

Entre os integrantes do grupo entrevistado, $44,4 \%$ tinham trabalho formal com carteira assinada, $22 \%$ atuaram de forma autônoma e os demais viviam de mesada, bolsa de estágio ou renda do cônjuge. Todos declararam receber entre um e três salários mínimos. O valor do salário mínimo em 2018, ano de aplicação do questionário, era de $\mathrm{R} \$ 937,00$. Quando indagamos sobre a renda da família, 66,7\% disseram que a renda 
SILVA, Letícia M. de S.; OLIVERIA, Sheila B. de; SANTOS, Rayanne E. da S. O repórter-amador: as disposições sociais de Lucas do Face. Caos - Revista Eletrônica de Ciências Sociais. João Pessoa, n. 23, p. 233 - 250, jul./dez. 2019. Disponível em: https://periodicos.ufpb.br/ojs2/index.php/caos/index

permanece entre um e três salários mínimos; $22,3 \%$ afirmaram que a renda fica entre três e seis salários mínimos, e 11,1\% disseram que a renda passa a casa dos seis salários mínimos. Do total do grupo, a maioria $(77,8 \%)$ morava em casa alugada, só uma pequena parcela $(22,2 \%)$ vivia em casa própria. Apesar de exercerem o papel de repórter-amador, ao serem questionados, apenas um se considerava jornalista, mesmo sem ter curso de graduação na área, três eram servidores públicos, três estudantes, um historiador e um se intitulava blogueiro.

Em relação ao mundo da educação, a maioria já iniciou algum curso superior, mas ainda não o concluiu. 66,7\% estavam nesse quadro. Já 22,2 \% terminaram a graduação e $11,1 \%$ ainda estavam no ensino médio. Todos afirmaram que a formação educacional estava, de alguma forma, vinculada à atividade profissional que exerciam. Sobre a religião, 77,8\% afirmaram que tinham uma crença. Eles estavam assim divididos: $44,4 \%$ católicos, 33,3\% protestantes e 11,1\% espíritas.

Em termos de atuação política, apenas 11,1\% disseram que integraram diretórios ou centros acadêmicos em colégio ou universidade, a grande maioria não tinha essa postura $(88,9 \%)$. Isso se refletiu na resposta sobre a filiação partidária. Só $22,2 \%$ estavam ligados formalmente a alguma legenda política. A maioria, inclusive, não votava considerando o partido do candidato: $55,6 \%$. Do grupo, $11,1 \%$ avaliavam "às vezes", $11,1 \%$ "frequentemente" e apenas $22,2 \%$ "sempre" consideravam a legenda do candidato quando iriam votar nas eleições. Sinalizando que a ideologia partidária não pesava na escolha do candidato, 44,44\% votavam "sempre" pela identificação pessoal com o político, 22,2\% “frequentemente”, 11,1\% “às vezes” e 22,2\% “nunca”. Quando a pergunta relacionou o voto às propostas dos candidatos, 77,8\% declararam que "sempre" votavam com base nessa vinculação. Apesar disso, apenas 44,4\% cobravam as promessas dos candidatos após as eleições.

Em relação à busca por informações, todos acessavam a internet de casa, do trabalho e do celular. $89,9 \%$ ficavam conectados por mais de três horas diariamente. Quando questionados sobre a busca por notícias em sites ou espaços nas redes sociais vinculados a empresas ou jornalistas, 44,4\% afirmaram que "sempre" recorriam a estas fontes de informação. 33,3\% faziam isso "frequentemente" e 22,2\% não responderam. 
SILVA, Letícia M. de S.; OLIVERIA, Sheila B. de; SANTOS, Rayanne E. da S. O repórter-amador: as disposições sociais de Lucas do Face. Caos - Revista Eletrônica de Ciências Sociais. João Pessoa, n. 23, p. 233 - 250, jul./dez. 2019. Disponível em: https://periodicos.ufpb.br/ojs2/index.php/caos/index

O que indica que o repórter-amador do Agreste consumiu informação da chamada grande imprensa. 66,6\%, inclusive, procuravam reportagens nos sites das empresas já veiculadas em jornais, revistas, televisões, rádios e mídias digitais. Só 11,1\% disseram que não faziam isso. 44,4\% enviavam imagens e textos para serem publicados ou subsidiarem matérias jornalísticas dos veículos de comunicação. 66,7\%, inclusive, colaboravam com mais de um veículo. Justificavam que tomavam essa atitude para: 1) interagirem com os jornalistas, 2) integrarem-se aos veículos e 3) influenciarem nas pautas da imprensa. 77,8\% dos entrevistados revelaram que gostariam de exercer a profissão de jornalista ou outra ligada à comunicação.

No mundo das redes sociais, as mais acessadas pelos atores para buscar informações eram Facebook (55,5\%), Instagram (44,4\%) e Twitter (33,3\%). 88\% do grupo procuravam blogs para obter informações, independentemente de serem ou não escritos por jornalistas. Mesmo percentual de entrevistados tinham o hábito de assistir aos vídeos do Youtube para se manter informados. Todos os entrevistados tinham alguma plataforma para criar notícia, seja blog, Youtube ou redes sociais, como Facebook, Instagram e Twitter.

O perfil geral do grupo, identificado aqui, e aprofundado na segunda fase da pesquisa, sinalizava que havia disposições sociais que os motivavam a agir ativamente no jornalismo, quando consumiam informação pela mídia tradicional ou não, interagiam com a imprensa e adotavam práticas jornalísticas ao criar espaços para produzir notícia. Do grupo, 66,7\%, ou seja, seis dos nove entrevistados, ganhavam dinheiro com essa atividade. No Agreste, ele está realizando essa ação também no tempo destinado ao trabalho. Na segunda fase da pesquisa, procuramos nos aprofundar no tema, deixando antever o forte indício de que está ocorrendo uma "profissionalização" do repórteramador, que produz notícia na/para internet, sem precisar de formação acadêmica especializada na área de jornalismo.

\section{Repórter-amador: o perfil sociológico}

Depois da elaborar um quadro geral com as características sociais, econômicas e culturais dos nove entrevistados na primeira fase da pesquisa, apresentamos, a partir de 
SILVA, Letícia M. de S.; OLIVERIA, Sheila B. de; SANTOS, Rayanne E. da S. O repórter-amador: as disposições sociais de Lucas do Face. Caos - Revista Eletrônica de Ciências Sociais. João Pessoa, n. 23, p. 233 - 250, jul./dez. 2019. Disponível em: https://periodicos.ufpb.br/ojs2/index.php/caos/index

agora, o perfil sociológico de Lucas do Face, o repórter-amador que faz notícias em Caruaru, cidade polo da Região Agreste de Pernambuco. Na segunda fase dessa investigação, selecionamos um ator de cada município para a análise dos perfis sociológicos. Lucas é formado em marketing e trabalha produzindo notícias para três redes sociais: Facebook, Instagram e Youtube, mas a principal delas é o Facebook. Nem sempre a vida dele foi assim. Criado na zona rural de Caruaru, herdou dos pais o hábito de escutar rádio, meio de comunicação que o fez gostar do mundo das notícias. Entretanto, não foi na comunicação que começou a trabalhar. Muitos jovens que nascem nas cidades de Caruaru, Toritama e Santa Cruz do Capibaribe, cidades do polo de confecção do Agreste, têm o primeiro emprego ligado aos fabricos, como são chamadas as fábricas artesanais, que funcionam na maioria das vezes dentro das casas das famílias. Lucas do Face começou de baixo, tirando os pelos dos tecidos.

Com o bom desempenho, foi subindo degraus e acabou se tornando gerente do negócio. Durante os anos desse trabalho, o rádio se tornou o grande companheiro das longas jornadas. Ele gostava de escutar os programas que debatiam política e informavam as notícias policiais. O hábito de estar informado o levou a querer saber além do que era mostrado pelas mídias. Queria descobrir como a informação era produzida e desejava repassar isso para as pessoas. Foi com essa ideia na cabeça que criou a sua página no Facebook em 2012. Não era para falar sobre ele, mas para deixar os cidadãos mais informados ou até mesmo trazer uma imagem da cidade. Quando aprendeu a entrar ao vivo, começou a transmitir os shows da festa típica da cidade: as festas juninas.

A página acabou se tornando um sucesso de curtidas, chegando a superar a audiência das páginas do Facebook de veículos tradicionais. O sucesso foi tanto que Lucas do Face abandonou o fabrico e foi se dedicar a fazer notícias pelas redes sociais em 2014. Ao ver o número de curtidas aumentar, também viu a necessidade de contratar pessoas que o ajudassem a produzir mais conteúdo. Atualmente, ele tem um pequeno time de colaboradores, que contribui na reportagem, na apuração, no marketing e na venda de propagandas. Ele percebeu que o conteúdo do Facebook também poderia estar em outras plataformas. Então, decidiu investir no Instagram e no Youtube, elaborando notícias e entretenimento para os seus seguidores. O desempenho nas outras plataformas tem sido positivo, o que o estimula ainda mais. 
SILVA, Letícia M. de S.; OLIVERIA, Sheila B. de; SANTOS, Rayanne E. da S. O repórter-amador: as disposições sociais de Lucas do Face. Caos - Revista Eletrônica de Ciências Sociais. João Pessoa, n. 23, p. 233 - 250, jul./dez. 2019. Disponível em: https://periodicos.ufpb.br/ojs2/index.php/caos/index

Nas quatro entrevistas em profundidade e sucessivas realizadas ao longo de seis meses, foi possível avaliar como Lucas do Face cresceu profissionalmente. Ele ganhou tanto prestígio que recebe ligações de suas fontes, como, por exemplo, gestores públicos de Caruaru e membros dos Poderes Executivo e Legislativo. Reservado, afirma que o principal motivo de seu trabalho é o de ajudar as pessoas com as suas notícias. Ele recebe muitas informações dos próprios internautas, que entram em contato com ele para passar imagens e textos de diversos acontecimentos de Caruaru e redondezas.

Para entender como as disposições sociais, motivadoras do repórter-amador foram sendo forjadas inconscientemente por Lucas do Face, é preciso compreender como elas foram sendo ativadas e apagadas ao longo de sua trajetória de vida, atravessando os mundos da família original (pai, mãe e irmão), da comunidade, da escola, do trabalho e do jornalismo. Lucas nasceu e morou na zona rural de Caruaru até os 12 anos de idade. Sempre viveu com o pai, a mãe e o irmão mais novo (PcD - Pessoa com deficiência), um motivo a mais que o levou a desempenhar o papel de ajudar o próximo. Destaca, porém, que a mãe é a sua influência mais forte, pois o pai precisava viajar muito a trabalho. A maior parte dos parentes vivia em residências próximas a dele, na zona rural. Durante a infância, não lembra das influências que recebeu dos pais para gostar de comunicação. Mas falou várias vezes de como ouvia rádio com eles para saber o que acontecia no mundo.

A mãe dele exercia a profissão de professora e era exemplo para ele, principalmente no desejo de ajudar o próximo. Ela participativa dos grupos da igreja católica, voltados para causas sociais, como a distribuição de alimentos a pessoas carentes. Durante a infância, ele chegou a ser coroinha e atuava de forma voluntária nos trabalhos com as comunidades. Ainda na infância, mudou-se para a zona urbana de Caruaru. Foi um choque perceber como as coisas eram tão diferentes. Aos poucos, foi se adaptando à vida mais agitada da cidade grande.

O padrinho dele, que também é seu tio, era policial militar. Ele o considerava um segundo pai. Assim, foi nascendo a paixão pela área de segurança, despertada quando ouvia as notícias do rádio, ao lado de seus pais, durante a infância. O gosto pela área policial se reflete nas postagens da sua página do Facebook, especialmente quando são 
SILVA, Letícia M. de S.; OLIVERIA, Sheila B. de; SANTOS, Rayanne E. da S. O repórter-amador: as disposições sociais de Lucas do Face. Caos - Revista Eletrônica de Ciências Sociais. João Pessoa, n. 23, p. 233 - 250, jul./dez. 2019. Disponível em: https://periodicos.ufpb.br/ojs2/index.php/caos/index

colocados vídeos de treinamento de policiais para combater a violência na cidade. É esse tio que o estimula a exercer o trabalho de repórter-amador nas redes sociais. Os outros membros da família não entendem como a atividade funciona. Lucas é diferente de todos os parentes próximos, que não compartilham da mesma paixão. É um caso de dissonância no mundo da família. Os pais, porém, percebem o prestígio do filho e reconhecem o seu trabalho.

Como o repórter-amador Lucas do Face foi influenciado pela escola? Ele estudou em escolas da rede pública até o ensino médio. Estudou em escolas da zona rural até a quinta série. Sentiu um grande impacto quando se mudou com a família para a cidade, pois a escola era maior e o ambiente era diferente. Com a mãe professora, foi incentivado a ler e escrever. Mas não se sentia motivado a participar de projetos escolares, como o grêmio estudantil, sendo um pouco tímido para realizar tais atividades. Durante o ensino médio, teve o incentivo dos professores para fazer o Exame Nacional do Ensino Médio (ENEM), porém, não ingressou imediatamente no ensino superior. Só veio a fazê-lo anos depois, entrando em uma universidade particular. Por meio de programa de financiamento do governo federal, começou o curso de Gestão, transferindo-se em seguida para o Curso de Marketing. É um dos poucos membros da família a ter um diploma universitário.

$\mathrm{Na}$ universidade, foi nascendo o interesse pelas redes sociais, suscitado por influência de professores. Com o tempo, o seu conhecimento sobre o tema já havia superado os dos seus influenciadores. A "curiosidade", que será uma disposição do repórter-amador, provavelmente deve ter se iniciado antes da universidade, durante as suas primeiras experiências socializadoras escolares. Quando tinha 11 anos de idade, foi uma professora de história que o estimulou a desenvolver o hábito da pesquisa, da leitura e da escrita.

Lucas do Face entrou cedo no mundo do trabalho. Ainda adolescente, começou a ajudar em uma facção de confecção para poder ter um pouco de dinheiro. Passou por alguns fabricos. Nesses locais, realizou vários serviços, iniciando com a tiragem de pelos. Quando estava trabalhando, sempre ficava ouvindo o rádio, preferindo os programas de debates, entrevistas e policiais, diferentemente dos outros empregados que gostavam de ouvir música. 
SILVA, Letícia M. de S.; OLIVERIA, Sheila B. de; SANTOS, Rayanne E. da S. O repórter-amador: as disposições sociais de Lucas do Face. Caos - Revista Eletrônica de Ciências Sociais. João Pessoa, n. 23, p. 233 - 250, jul./dez. 2019. Disponível em: https://periodicos.ufpb.br/ojs2/index.php/caos/index

Com bom desempenho, foi crescendo e chegou ao cargo de gerente. Mas quando criou a página no Facebook e começou a escrever, resolveu arriscar no papel de repórteramador. Deixou o comércio de roupas e dedicou o seu tempo à sua página no Facebook. Começou postando vídeos. Depois, fez lives para transmitir ao vivo as festas locais. As pessoas gostavam e acompanhavam as postagens. Iniciou com notícias da área policial. Transmitia do local dos acontecimentos: um crime ou um grave acidente. Foi ganhando seguidores, fontes e credibilidade. Passou a servir de modelo para outras páginas de outros repórteres-amadores do Agreste.

Mesmo sem ser formado em jornalismo, ele se tornou uma fonte de informação para o público, chegando a ter mais que o dobro de curtidas das emissoras de comunicação da região. Ele posta a notícia com exclusividade nas lives e passa à frente dos telejornais das mídias tradicionais da cidade. Hoje, uma grande emissora local, fez um contrato de parceria com o espaço de Lucas do Face, transmitindo informações apuradas por ele e sua equipe. Ele passou a contratar jornalistas formados para atuar em sua equipe. Atualmente, ele não está apenas no Facebook, tem contas no Instagram e no canal do Youtube.

\section{Considerações finais}

No questionário exploratório da primeira fase da pesquisa, observamos que os nove indivíduos entrevistados conseguem dinheiro produzindo notícias patrocinadas. Eles afirmam, entretanto, que isso não interfere no conteúdo que querem que seja exibido nos seus espaços autorais, apesar de colocarem a marca do anunciante. A remuneração é conquistada por eles com mais de uma modalidade de trabalho. Alguns conseguem, inclusive, manter-se financeiramente somente com a atuação nas redes sociais.

Além da notícia com a marca do anunciante, eles também afirmaram que recebem por matéria paga. Ou seja, recebem para fazer uma determinada notícia para que ela seja exibida nos blogs ou nas redes sociais. Ganham ainda por meio do instrumento de monetização via Google. Nesse sentido, a maioria é empreendedora. Assim, colabora para o desenvolvimento local e regional, pois emprega outros atores para ajudar na produção do conteúdo. 
SILVA, Letícia M. de S.; OLIVERIA, Sheila B. de; SANTOS, Rayanne E. da S. O repórter-amador: as disposições sociais de Lucas do Face. Caos - Revista Eletrônica de Ciências Sociais. João Pessoa, n. 23, p. 233 - 250, jul./dez. 2019. Disponível em: https://periodicos.ufpb.br/ojs2/index.php/caos/index

Outro dado que chamou atenção no momento de avaliar as práticas do cidadão comum no mundo do jornalismo, foi o fato de, na primeira fase, todos interagirem com mais de um veículo de comunicação. A forte disposição para agir ativamente foi expressa, ainda, pela vontade que sete indivíduos entrevistados revelaram: o do sonho de estudar jornalismo para exercerem essa atividade de forma profissional, e o de ser reconhecidos pelo título de jornalista. Os integrantes do grupo, que revelaram o sonho de estudar para ser profissional da área, vincularam essa vontade ao gosto pela leitura e pela escrita, e ao desejo de informar os outros atores sobre os problemas das comunidades em que viviam.

$\mathrm{Na}$ segunda fase da pesquisa de campo, os repórteres-amadores revelaram, de forma inconsciente, como foram surgindo as disposições sociais para a produção de conteúdo, vinculando essas inclinações às motivações para as ações políticas, sociais, religiosas e culturais. No caso de Lucas do Face, um dos três que foram entrevistados de forma profunda e sucessiva, essas motivações foram nascendo nos mundos da família, da escola e do trabalho.

Apesar do corpus desta pesquisa ser pequeno, lastreado em nove entrevistas na fase inicial, o que traz limitação para generalizações, os dados coletados na primeira fase permitem identificar algumas características gerais. Elas irão contribuir para subsidiar a análise mais profunda da fase seguinte, mesmo porque o objetivo principal da pesquisa é aproximar o foco dos universos dos indivíduos que acionam esquemas disposicionais para agir ativamente no jornalismo. Nela, foram feitos perfis sociológicos de três repórteresamadores, um de cada cidade observada: Caruaru, Bezerros e Toritama.

Todos os entrevistados nessa primeira fase, localizados em um mapeamento de espaços autorais feitos nas redes sociais de moradores do Agreste, expressaram ter necessidade de se manter informados e constantemente atualizados, procurando mídias tradicionais e espaços na internet. A maioria consultava sites de veículos de comunicação e espaços nas redes sociais, sem se restringir aos que eram produzidos exclusivamente por jornalistas. Todos tinham plataforma própria para produzir notícia, contrapondo-se aos veículos tradicionais de comunicação. A maioria ganhava dinheiro com esse espaço e gostaria de ser reconhecida como jornalista. 
SILVA, Letícia M. de S.; OLIVERIA, Sheila B. de; SANTOS, Rayanne E. da S. O repórter-amador: as disposições sociais de Lucas do Face. Caos - Revista Eletrônica de Ciências Sociais. João Pessoa, n. 23, p. 233 - 250, jul./dez. 2019. Disponível em: https://periodicos.ufpb.br/ojs2/index.php/caos/index

Com base nesses dados, pode-se afirmar que há uma relação significativa entre o indivíduo que busca informação nos veículos de comunicação e a disposição de querer agir como repórter-amador, como foi o caso de Lucas do Face. Do ponto de vista da comunicação, é importante pesquisar as disposições sociais dos repórteres-amadores do Agreste, pois são eles que fazem o contraponto da informação, produzida, editada e publicada pelos veículos da chamada grande imprensa, que atuam na região e são controlados por fortes grupos empresariais e políticos. As ferramentas surgidas com as redes sociais, criaram facilidades de comunicação para o cidadão que não quer ficar refém da mídia tradicional, mas quer inovar e produzir o próprio conteúdo.

É fundamental salientar, ainda, que a cidade de Caruaru passou a ter vários repórteres-amadores desde que o acesso à internet foi ampliado e o uso do smartphone se transformou em algo popular. Essas pessoas geralmente se escondem por trás de uma página no Facebook, mas, mesmo assim, têm se tornado reconhecidas. O universo de pessoas que atuam como repórteres-amadores, sem realmente serem formados na profissão de jornalista, só aumenta.

Algumas dessas páginas têm se tornado mais acessadas do que os espaços da mídia tradicional caruaruense nas redes sociais, uma vertente da pesquisa que poderá ser aprofundada em outra fase da investigação. O trabalho de campo também sinalizou que os municípios do Agreste estudados têm ganhado, a cada dia, um maior número de cidadãos que não se contenta mais em desempenhar somente o papel de audiência passiva e passa a querer produzir a notícia, uma tendência que se reflete no mundo contemporâneo.

\section{Referências}

BORGES, S. O repórter-amador: uma análise das disposições sociais motivadoras das práticas jornalísticas do cidadão comum. Recife: Editora Cepe, 2015.

MORETZSOHN, S. Pensando contra os fatos. Jornalismo e cotidiano: do senso comum ao senso crítico. Rio de Janeiro: Revan, 2007.

LAHIRE, B. O homem plural. Petrópolis, RJ: Vozes, 2002.

LAHIRE, B. Retratos sociológicos: disposições e variações individuais. Porto Alegre: Artmed, 2004. 
SILVA, Letícia M. de S.; OLIVERIA, Sheila B. de; SANTOS, Rayanne E. da S. O repórter-amador: as disposições sociais de Lucas do Face. Caos - Revista Eletrônica de Ciências Sociais. João Pessoa, n. 23, p. 233 - 250, jul./dez. 2019. Disponível em: https://periodicos.ufpb.br/ojs2/index.php/caos/index

LAHIRE, B. A cultura dos indivíduos. Porto Alegre: Artmed, 2006.

LAHIRE, B. Por uma sociologia disposicionalista e contextualista da ação. In: JUNQUEIRA, L.(org ). Cultura e classes sociais na perspectiva disposicionalista. Recife: Editora Universitária da UFPE, 2010, p. 17-36.

SBARAI, R. S. A. Minha notícia, IReport e OhmyNews: modelos de cooperação ou colaboração no jornalismo digital? In: LIMA JUNIOR, W. T. (Org.). Comunicação, tecnologia e cultura de rede. São Paulo: Momento Editorial, 2011, p. 12-39. Disponível em: http://www.livroteccred.blogspot.com. Acesso em: 10/10/2018.

WOLF, M. Teorias da comunicação. Lisboa: Editorial Presença, 1987.

Recebido em: 23/09/2019.

Aceito em: 03/10/2019. 